\title{
Modelos internacionais de educação superior: Estados Unidos, França e Alemanha
}

\author{
Wellington Tischer ${ }^{1}$ \\ Universidade Federal da Fronteira Sul, Arquiteto e Urbanista. \\ http://orcid.org/0000-0002-3952-5010
}

MORAES, R. C. C. de; SILVA, M. de P. e; CASTRO, L. C. de. Modelos internacionais de educação superior Estados Unidos, França e Alemanha. São Paulo: Editora UNESP, 2017. १16 p.

A obra Modelos Internacionais de Educação Superior - Estados Unidos, França e Alemanha, publicada pela Editora UNESP em 2017, possui quatro capítulos intitulados Universidades norte-americanas na virada do novo milênio; 0 caso francês: um sistema peculiar; A educação Superior na Alemanha: uma tentativa de descrição e interpretação; e Notas sobre - Sistema dual alemão. A obra nos oferece, conforme prometido na apresentação, uma visão sintética dos sistemas de educação superior mais reproduzidos mundialmente, e, portanto, o texto é didático e descritivo. Para compreensão do leitor, a obra apresenta quadros, gráficos e tabelas para demonstrar a evolução desses sistemas universitários tradicionais.

No primeiro capítulo é descrita a expansão do conjunto de universidades nos Estados Unidos calcada na pesquisa e inovação privada e financiada, majoritariamente, por recursos públicos que têm mudado de forma e organização a partir dos anos 1980 para atendimento do setor privado com fins lucrativos em detrimento do setor non-profit. 0 conjunto de instituições conforma um modelo de pirâmide conforme descrito em Modelos Internacionais, com universidades de pesquisa no topo, um segundo estrato de universidades consideradas "doutorais" e na base estão universidades estaduais e colleges, com cursos de graduação e mestrado, e as communities colleges, com grande dispersão no território. No "sistema" descrito por Reginaldo Moraes, as escolas privadas contemplam os cursos mais prestigiosos enquanto as escolas públicas diversificam especialidades e carreiras. A partir dos anos 2000 , as universidades norte-americanas, pouco seletivas e voltadas à massificação, ficaram cada vez mais dependentes de fontes públicas, operando a baixos custos para segmentos mais pobres e conferindo alto endividamento de indivíduos e das famílias, com efeitos negativos descritos em Modelos Internacionais, como grande evasão, alongamento dos tempos de conclusão para os alunos e precarização do trabalho docente no "lado ensino". Enquanto no "lado pesquisa", houve, a partir de 1990, uma mudança na origem e destino para o setor industrial das verbas de Pesquisa e Desenvolvimento (P\&D) por meio de renúncias fiscais.

Mestre e doutorando em Planejamento Territorial e Desenvolvimento Socioambiental pela Universidade do Estado de Santa Catarina. 
Ainda, a criação das Unidades de Pesquisa Organizada (ORU) conferiu uma "automatização" da pesquisa, garantindo a contratação de docentes, a disponibilização de bolsas e a obtenção de fundos em proporção maior do que matrículas.

Para Reginaldo Moraes, trata-se de "invenção norte-americana que procura dar resposta à necessidade de produzir pesquisa encomendada e combiná-la com a atividade "tradicional" das universidades" (p. 27). Em Modelos internacionais, as ciências da vida, com destaque à biologia e à medicina, tiveram seu foco deslocado da pesquisa básica para a prática clínica, como o desenvolvimento de procedimentos, aparelhagens e fármacos ligado ao tratamento e cura de doenças selecionadas pela "indústria" da saúde, elevando esse filão com maior representação na captação de recursos (56\%). Por isso, possuir instalações médicas modernas e as "mercadorias valiosas", que são os docentes, configura uma condição especial de atratividade para a obtenção de recursos e afeta, também, as relações internas de força, poder e prestígio nas universidades. Além da "indústria da saúde", o "mundo dos negócios" tem tendencialmente se beneficiado da transformação do modelo universitário norte-americano, conformando parcerias com corporações. Esse é o modelo adotado pela MIT, Stanford e Yale para fazer pesquisa dirigida, atraindo alunos prodígios e multiplicando patentes e licenças, segundo Moraes. Ao final, Reginaldo Moraes nos oferece um panorama do recente crescimento do minoritário ensino superior privado com fins lucrativos a partir dos anos 2000. 0 insucesso nesse segmento, segundo o autor, está na modalidade de financiamento, que é costurado no limite da irresponsabilidade da dívida estudantil a partir do gap deixado pelo aumento de mensalidades dos setores público e privado non-profit. 0 autor ainda sugere uma reflexão para países que tentam replicar esse segmento do modelo.

No capítulo 0 caso francês: um sistema peculiar, Reginaldo Moraes descreve o sistema francês como um "cipoal" de escolas, cursos e diplomas diferenciados dos sistemas binários, com universidades de herança tradicional, e unitários, com escolas profissionais de saberes aplicados no corpo de universidades. No contexto francês, conforme Moraes, as universidades estiveram longe de constituir um corpo único e com autonomia (p. 50) em um quadro expansivo ao longo do século XX com segmentos diferentes: das Universidades e "assimilados", das Grands Établissements em pequeno número, renome e muito seletivas, das classes preparatórias para grandes escolas com liceus preparatórios, e das Sections Techniques Supérieurs - STS com grande capilaridade regional no território francês e cursos com cerca de 100 especialidades. Reginaldo Moraes também descreve o impacto da reforma do Processo de Bologna com etapas de formação e as fases do percurso formativo passando pelos liceus preparatórios, graduações, mestrado e doutorado como um sistema pequeno e fechado que é pressionado pelo crescimento econômico e demográfico. Segundo o autor, os liceus funcionam como filtro seletivo para as elites pública e privada e também fornecem para a grande massa diplomas de tecnólogos de nível pós-secundário nas STS (p. 53). 
A trajetória francesa recente em diversificação das instituições e cursos como os baccalauréat (bacs) exprime uma tendência para cursos de formação tecnológica e profissional e imposição de barreiras de nível como a evasão, que combinam inclusão e filtragem para os níveis superiores a partir da lógica de expansão. A expansão francesa, segundo Moraes, trata da criação de novas universidades e de antennes universitaires (campus auxiliares) de universidades existentes. Reginaldo Moraes, ainda, esclarece que $85 \%$ do gasto nacional na França são públicos e que o financiamento é bastante centralizado sob a tutela do Ministério da Educação, ainda que haja um encorajamento ao comportamento de mercado. Sendo um segmento relevante no contexto francês com origem no ensino médio profissionalizante, além das STS, os Institute Universitaires de Tecnologie (IUT), com ambiente universitário exigente, muito regulado, com presença obrigatória, grupos de trabalho dirigido e estágios (p. 58) para carreiras de eletrônica, mecânica e construção civil, incentivam a penetração de grandes centros e laboratórios de pesquisa nas universidades (p. 59). Nas duas pontas do modelo francês estão, segundo o autor, as Grandes Escolas, com a seletiva de elite, e os STS, com seletivas populares funcionando dentro dos liceus, que são um andar superior do ensino médio francês. Dentro do modelo de "classes preparatórias", alguns liceus de ponta operam um filtro para Grandes Escolas, enquanto o STS passa a ser uma oportunidade de acesso "perto de casa" (p. 63) para descentralização do ensino e voltado às classes populares, para obterem diplomas profissionalizantes.

0 terceiro capítulo, intitulado $A$ Educação Superior na Alemanha: uma tentativa de descrição e interpretação, escrito por Maitá de Paula e Silva, contempla a evolução no modelo humboltiano de universidade com unidade de ensino e pesquisa livre de interesses e calcado em ideais humanistas após a descentralização das instituições que se encontram sob administração dos Länder (províncias da federação) após a unificação. Segundo a autora, as reformas aplicadas pelo Estado alemão com a criação de novas universidades entre 1960 e 1980, a massificação e diversificação das instituições das quais as Fachhochshculen (Fachs), que são escolas superiores com enfoque técnico e aplicado, são os principais aspectos de evolução do modelo alemão. Em meados dos anos 1970, segundo a autora, o sistema alemão teve que dirimir os problemas decorrentes de um modelo verticalizado combinado com diferentes modalidades de ensino secundário de pouca mobilidade na carreira, e um sistema de alocação de alunos colocou uma forte tendência ao controle federal, que teve que conviver com a deterioração dos recursos e a instalação das universidades em geral por conta de efeitos da massificação (p. 78).

Para Maitá de Paula e Silva, a particularidade dos programas vocacionais (sistema dual) colocou ênfase no tipo de escola secundária, definindo a carreira do aluno a partir dessa escolha. Outro aspecto apontado pela autora é o recente aumento de numerus clausus (vagas limitadas) em cursos das áreas de tecnologia ao lado de cursos com barreiras tradicionais como ciências da vida, por exemplo. As Fachs variam em tamanho, número de alunos e número 
de cursos e têm forte relação regional com área particular de especialização e diversificação, com cerca de cinco mil diferentes diplomas de Bacharel. A partir dos anos 1990, teve início a implantação de um modelo inspirado da Nova Administração Pública (NAP) com reflexos na gestão por qualidade e regulação por parte de dirigentes da administração da universidade e comitês externos. Outra particularidade abordada por Maitá de Paula e Silva é a presença de exame estatal (Staatsprüfung) para algumas áreas das ciências da vida e engenharia e de novas condições de admissão menos rígidas no ensino superior, rompendo com a trajetória estruturante do percurso formativo alemão. Ainda, a autora aborda o financiamento, que coloca expectativas na competição e encoraja as instituições de ensino superior a focar no fornecimento do melhor custo-benefício de um modelo de "insumo" para um modelo de "produto", com métodos específicos de garantia de desempenho, em que haverá perdedores entre instituições e dentro delas (p. 94). Ainda que controversa, Modelos internacionais explica como o pagamento de mensalidades não resistiu a pressões populares e foi um refluxo desse movimento de NAP que contempla hoje um programa de bolsas e crédito estudantil com critérios mais ajustados à realidade dos estudantes na dotação de bolsas em uma cultura de patrocínio de entidades da sociedade civil, como partidos, sindicatos, igrejas, indústrias e doadores individuais.

Luiza Carnicero de Castro complementa, no capítulo final denominado Notas sobre - Sistema Dual alemão, o que se delineava no modelo descrito no capítulo anterior, como a relação entre capital industrial e ensino superior baseado na inovação adaptativa com enlace entre o "chão de fábrica" e os "bancos das universidades", sendo esse o grande prestígio atual do modelo-referência para nações industrializadas por ser um sistema dual que combina treinamento vocacional e aprendizado teórico. Esse sistema dual vem sendo entendido como uma das razões dos baixos índices de desemprego entre jovens e tem raízes nas políticas educacionais dos anos 1960 para combate às desigualdades, sendo o Instituto Federal para Treinamento Vocacional (BIBB), subordinado ao Ministério da Educação e Ciência, responsável pela ampliação e atualização do sistema. Luiza de Castro destaca, também, o incentivo à participação de cursos vocacionais para a competitividade do mercado de trabalho como fator de desempenho no plano individual e à mobilização dos sindicatos como fator de desempenho para a qualificação de aprendizes que recebem salários menores e certificados disponibilizados pelos tutores obtidos por etapas nos estágios de formação. 0 financiamento desses cursos vocacionais é dividido entre os governos estaduais (Länder), empresas privadas e os próprios aprendizes (p. 107) e corresponde a uma vantagem para empresas para a captação de profissionais.

Como atores externos a esse sistema dual, Luiza Carnicero de Castro aponta autoridades públicas, organizações empresariais e sindicatos que estabelecem os programas por meio de longo processo participativo. Outro problema com o qual o sistema dual teve que conviver foi o da reunificação alemã com o atraso oriental resolvido mediante a criação de 
novas estruturas privadas e, recentemente, com a adaptação de seu modelo para qualificação e internacionalização integrando a Alemanha à União Europeia por meio da adesão da Estratégia de Lisboa, como aponta Modelos Internacionais. Novos desafios com uma reforma para atualização tecnológica, diminuição dos cursos e atualização dos programas, que vêm sofrendo críticas pela baixa integração das novas profissões ao mercado de trabalho no setor de serviços, são apontados pela autora.

Modelos internacionais de Educação Superior é uma obra de fácil leitura e compreensão por parte do leitor que busca compreender um pouco mais sobre a evolução dos modelos que permeiam o debate universitário. 0s modelos norte-americano, francês e alemão são constantemente acionados em debates sobre os rumos da educação superior independente do atual Estado da Arte, e os autores nos brindam com uma contribuição em um momento histórico no qual o sistema universitário atualmente em expansão vem sendo colocado em suspeição, principalmente com relação ao financiamento público federal.

Recebido em 7 de novembro de 2020 Aceito em 5 de fevereiro de 2019 Publicado em 22 de junho de 2020

Endereço para correspondência: Avenida Fernando Machado, 108e, Centro, Chapecó, Santa Catarina, Brasil; wellington.tischer@outlook.com

Roteiro, Joaçaba, u. 45, p. 1-4, jan./dez. 2020 | e23416 |E-ISSN 2177-6059 
